Leonard H. Calabrese, DO

Department of Rheumatic and Immunologic Diseases,

Orthopedic \& Rheumatologic Institute, Cleveland Clinic;

Professor, Cleveland Clinic Lerner College of Medicine of Case

Western Reserve University, Cleveland, $\mathrm{OH}$
Cassandra Calabrese, D0

Department of Rheumatic and Immunologic Diseases,

Orthopedic \& Rheumatologic Institute, and Department

of Infectious Disease, Cleveland Clinic

\title{
Cytokine release syndrome and the prospects for immunotherapy with COVID-19. Part 2: The role of interleukin 1
}

\section{Posted June 24, 2020}

\section{ABSTRACT}

Interleukin 1 (IL-1) is a potential target of therapy in COVID-19 during the severe respiratory-inflammatory phase ("cytokine release syndrome"), when pulmonary macrophages are hyperactivated, releasing IL-1 and other cytokines. Preliminary evidence indicates that anakinra and canakinumab, drugs that block the action of IL-1 and have a good safety profile, improve the outcomes of patients with COVID-19 cytokine release syndrome. Results from large, randomized clinical trials are pending.

\section{INTRODUCTION}

In an earlier article, ${ }^{1}$ we outlined a theoretic construct of immunopathogenesis in COVID-19 in which the disease progresses through 3 stages. Since that time (about 1 month ago), our vision and understanding have evolved, integrating a number of other biomarkers and considerations (Figure 1). Our goal is to apply our new paradigm to the design of therapeutic trials. This model newly notes the critical role of coagulation, coagulopathy, and complement activation, which appear to contribute to the morbidity and mortality associated with progressive inflammation. We refer to this severe respiratory-inflammatory phase as cytokine release syndrome (CRS).

While many observers have drawn on the similarities between CRS in COVID-19 and secondary hemophagocytic lymphohistiocytosis, macrophage activation syndrome, and cytokine storm due to chimeric antigen receptor T-cell therapy, these conditions are for the most part clinically and immunopathologi-

The statements and opinions expressed in COVID-19 Curbside Consults are based on experience and the available literature as of the date posted. While we try to regularly update this content, any offered recommendations cannot be substituted for the clinical judgment of clinicians caring for individual patients.

doi:10.3949/ccjm.87a.ccc044 cally distinct..$^{2-4}$ Similarities between COVID-19 and these other causes of cytokine storm include shared elevations of cytokines such as interleukin 1 (IL-1), interleukin 6 (IL-6), and tumor necrosis factor (TNF) and some evidence demonstrating hemophagocytosis in pulmonary beds, while differences include quantitative differences in certain biomarkers among these disorders and paucity of peripheral end-organ dysfunction in COVID-19 in the absence of clotting complications. ${ }^{2}$ Analysis of soluble and cell-expressed inflammatory biomarkers and cytokines has demonstrated that in progressive CRS, a number of these mediators are overexpressed, including IL-6, IL-1, TNF, interleukin 2 receptor (IL-2R), interleukin 10 (IL-10), interleukin 18 (IL-18), granulocyte-macrophage colony-stimulating factor (GM-CSF), granulocyte colony-stimulating factor (G-CSF), gammainterferon, and numerous chemokine receptors. ${ }^{3}$

As of May 18, 2020, over 900 COVID-19 trials have been registered at www.clinicaltrials.gov, many of which are therapeutically targeting the cytokine release stage of COVID-19 with either single or multiple agents. These candidate therapies under investigation include biologics as well as targeted synthetic agents (eg, kinase inhibitors), cellular therapies, and devices. Cytokine-targeting agents such as inhibitors of IL-6, TNF, GM-CSF, gamma-interferon, and IL-1 are the most promising thus far. Our earlier article focused on IL-6 as a target of treatment; the remainder of this article focuses on IL-1.

\section{RATIONALE FOR TARGETING IL-1}

IL-1 includes 2 distinct cytokines, IL-1 alpha and IL-1 beta. Along with IL-1 receptor antagonist (IL-1RA) and IL-18, these molecules play important roles in the acute inflammatory response. Interest in IL-1 in COVID19 stems from the utility of targeting it in a variety of 


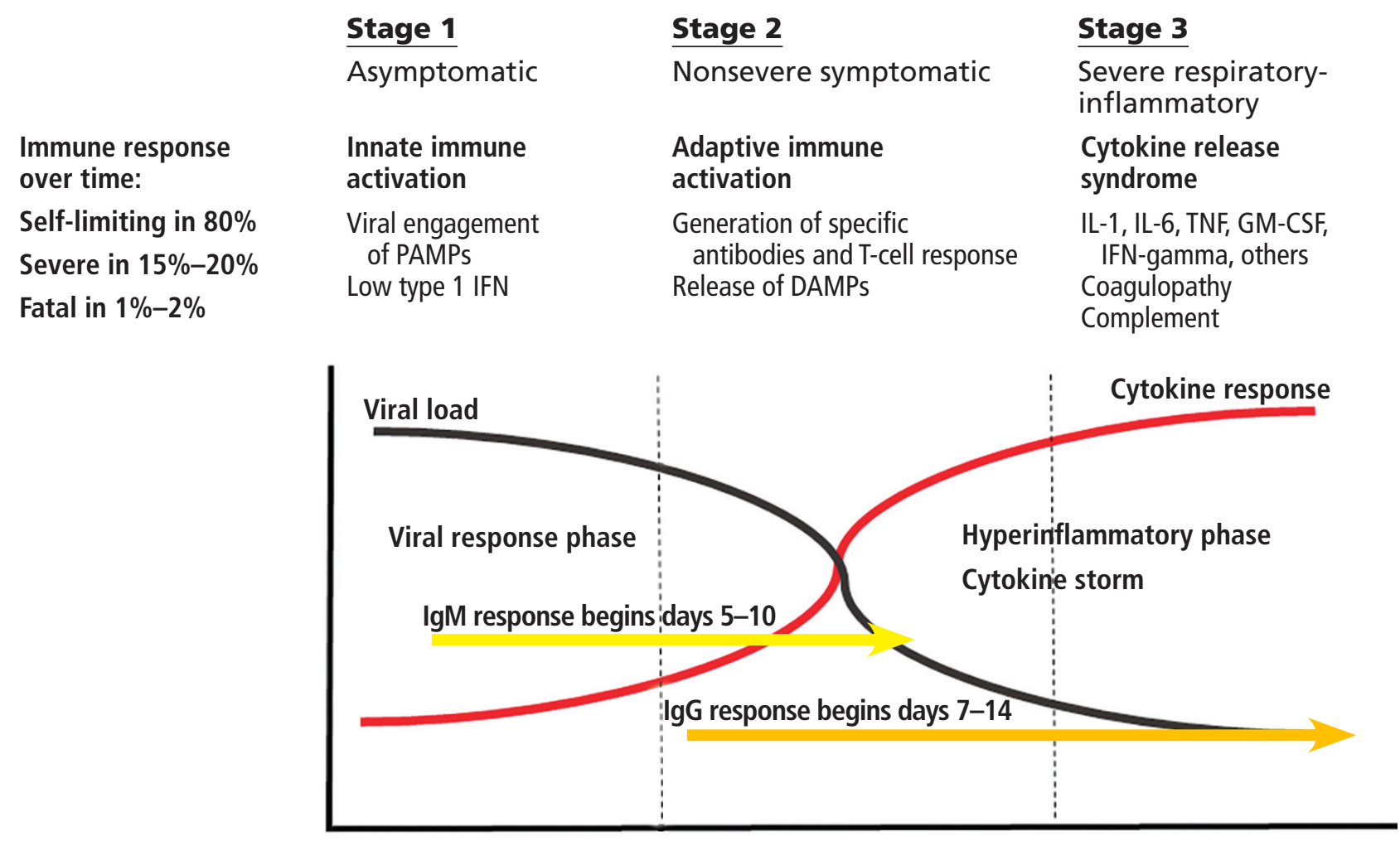

Time course

DAMPs = damage-associated molecular patterns; GM-CSF = granulocyte macrophage colony-stimulating factor; IFN = interferon; IgM = immunoglobulin M; IL-1 = interleukin 1; IL-6 = interleukin 6; PAMPs = pathogen-associated molecular patterns; TNF = tumor necrosis factor

Figure 1. Three stages of COVID-19 disease.

From Calabrese LH. Cytokine storm and the prospects for immunotherapy with COVID-19. Cleve Clin J Med 2020; 87(7):389-393. doi:10.3949/ccjm.87a.ccc008

immune-mediated disorders; drugs of this class have approved indications for treating rheumatoid arthritis, systemic juvenile idiopathic arthritis, cryopyrin-associated periodic syndromes, and familial Mediterranean fever (Table 1), in which IL-1 is similarly elevated (as are other cytokines such as IL-6 and IL-18). ${ }^{5}$

Of even greater interest is the utility of targeting IL-1 in the nonapproved indications of secondary hemophagocytic lymphohistiocytosis and macrophage activation syndrome, which display many immunologic and clinical features similar to the cytokine release phase of COVID-19. ${ }^{6}$

IL-1 is a product of the activated inflammasome, a cytosolic multiprotein oligomer that can be activated by a variety of triggers, including infectious agents and endogenous danger signals generated by dying cells and activated platelets. IL-1 is produced primarily by macrophages and monocytes, cells that have been incriminated in the pathogenesis of the inflammatory phase of COVID-19 after being detected in the lung by single-cell RNA sequencing accompa- nied by the detection of elevated IL-1 in bronchial alveolar lavage fluid. ${ }^{7}$ It is postulated that in COVID19 , pulmonary macrophages are hyperactivated either directly by the virus or indirectly by the products of damaged tissues, or both. Of note, pulmonary macrophages and their elaborated cytokines are also considered central in the pathogenesis of acute respiratory distress syndrome, which can occur with COVID-19 infection. ${ }^{8}$

With several approved IL-1-targeting agents available, as of this writing, more than 10 trials in COVID-19 have been registered and 3 studies have recently been completed. ${ }^{9-11}$ One of the completed studies is an open-label, noncontrolled series of 9 cases in which the recombinant IL-1 receptor antagonist anakinra was used at a dose of $100 \mathrm{mg}$ every 12 hours. The patients were described as having advancing disease and responded with clinical defervescence documented by the halting of progression on chest radiographs. There were no deaths. ${ }^{9}$

In a second and larger, albeit retrospective trial, ${ }^{10}$ 
TABLE 1

Currently available interleukin 1 inhibitors

\begin{tabular}{|c|c|c|c|}
\hline Agent & $\begin{array}{l}\text { Mechanism } \\
\text { of action }\end{array}$ & $\begin{array}{l}\text { Current FDA-approved } \\
\text { indications and dosing }\end{array}$ & $\begin{array}{l}\text { Contraindications } \\
\text { and cautions }\end{array}$ \\
\hline \multirow[t]{3}{*}{$\begin{array}{l}\text { Anakinra } \\
\text { (Kineret) }\end{array}$} & $\begin{array}{l}\text { Recombinant human IL-1 } \\
\text { receptor antagonist }\end{array}$ & $\begin{array}{l}\text { Rheumatoid arthritis: } 100 \text { mg subcutaneously } \\
\text { once a day }\end{array}$ & $\begin{array}{l}\text { Use with caution in patients } \\
\text { with: }\end{array}$ \\
\hline & \multirow[t]{2}{*}{$\begin{array}{l}\text { Inhibits activity of IL-1 } \\
\text { alpha and IL-1 beta }\end{array}$} & $\begin{array}{l}\text { CAPS/NOMID: } 1-2 \mathrm{mg} / \mathrm{kg} \text { subcutaneously once } \\
\text { a day; can increase by } 0.5-1 \mathrm{mg} / \mathrm{kg} \text { increments; } \\
\text { maximum dose } 8 \mathrm{mg} / \mathrm{kg}\end{array}$ & \multirow[t]{2}{*}{$\begin{array}{l}\text { Concomitant TNF inhibitor use } \\
\text { Serious active infection } \\
\text { Neutropenia }\end{array}$} \\
\hline & & $\begin{array}{l}\text { Renal dosing: if creatinine clearance is }<30 \mathrm{~mL} / \\
\text { min or patient is in end-stage renal disease, consider } \\
\text { alternate dosing }\end{array}$ & \\
\hline \multirow[t]{6}{*}{$\begin{array}{l}\text { Canakinumab } \\
\text { (Ilaris) }\end{array}$} & \multirow{6}{*}{$\begin{array}{l}\text { Human monoclonal anti- } \\
\text { IL-1 beta } \\
\text { Neutralizes IL-1 beta } \\
\text { activity }\end{array}$} & \multirow{2}{*}{$\begin{array}{l}\text { Systemic juvenile idiopathic arthritis: } 4 \mathrm{mg} / \mathrm{kg} \\
\text { subcutaneously once a month; not to exceed } 300 \\
\text { mg/dose ( } \geq 2 \text { years and weight } \geq 7.5 \mathrm{~kg} \text { ) }\end{array}$} & \multirow[t]{6}{*}{$\begin{array}{l}\text { Use with caution in patients } \\
\text { with serious active infection }\end{array}$} \\
\hline & & & \\
\hline & & $\begin{array}{l}\text { CAPS: If } 15-40 \text { kg, } 2 \text { mg/kg subcutaneously every } \\
8 \text { weeks }\end{array}$ & \\
\hline & & If $\geq 40$ kg, 150 mg subcutaneously every 8 weeks & \\
\hline & & $\begin{array}{l}\text { FMF, TRAPS and HIDS/MVD: If } \leq 40 \mathrm{~kg}, 2 \mathrm{mg} / \mathrm{kg} \\
\text { subcutaneously every } 4 \text { weeks, can increase to } 4 \mathrm{mg} / \\
\text { kg every } 4 \text { weeks }\end{array}$ & \\
\hline & & $\begin{array}{l}\text { If > } 40 \mathrm{~kg}, 150 \mathrm{mg} \text { subcutaneously every } 4 \text { weeks; } \\
\text { can increase to } 300 \text { mg every } 4 \text { weeks }\end{array}$ & \\
\hline
\end{tabular}

Rilonacept

(Arcalyst)

\author{
Fusion protein of \\ extracellular domains of \\ IL-1-RACP and IL-1-R1 \\ fused to FC portion of \\ human $\lg \mathrm{G} 1$ \\ Binds to IL-1 alpha and \\ IL-1 beta to block IL-1 \\ signaling
}

\section{CAPS:}

Adults-loading dose $320 \mathrm{mg}$ subcutaneously, followed by $160 \mathrm{mg}$ subcutaneously weekly Children (12-17 years) -loading dose of $4.4 \mathrm{mg} /$ $\mathrm{kg}$ (maximum dose $320 \mathrm{mg}$ ), followed by $2.2 \mathrm{mg} / \mathrm{kg}$ subcutaneously weekly (maximum dose $160 \mathrm{mg}$ )
Use with caution in patients with serious active infection

CAPS = cryopyrin-associated periodic syndromes; FC = fragment crystallizable; FMF = familial Mediterranean fever, HIDS/MKD = hyperimmunoglobulin D syndrome/mevalonate kinase deficiency; IG = immunoglobulin; IL = interleukin; IL-1-RACP = IL-1 receptor accessory protein; IL-1-R1 = interleukin 1 receptor, type I; NOMID = neonatal-onset multisystem inflammatory disease; TNF = tumor necrosis factor; TRAPS = tumor necrosis factor receptor associated periodic syndrome

anakinra was used in a higher dose $(5 \mathrm{mg} / \mathrm{kg}$ twice a day intravenously or $100 \mathrm{mg}$ twice a day subcutaneously) for a variable time period guided by response, combined with a regimen of hydroxychloroquine and ritonavir-lopinavir. Outcomes at day 21 were compared with those of a similar group treated with the same drug regimen without anakinra. At 21 days, the anakinra group had lower levels of inflammatory markers and milder clinical courses than the control group, with a $10 \%$ mortality rate in the active treatment group vs $44 \%$ in the control group. Of note, 7 patients treated initially with a lower-dose regimen of anakinra were later given the higher dose because of minimal effects on laboratory and clinical param- eters after 7 days; all had favorable responses. Overall, safety was good, with clinical improvement in $72 \%$.

The third trial ${ }^{11}$ is of particular interest because of its size (with 52 patients receiving anakinra and 44 historical controls) and the degree by which it reduced (by 48\%) either the need for mechanical ventilation or death. While this relative risk reduction is impressive, the design limits the strength of any conclusions, as the comparator group was retrospectively derived and unmatched in certain clinical features. Both groups also received numerous other therapies, including hydroxychloroquine and azithromycin. Large prospective trials are now underway and should provide meaningful data on the potential 
merit of IL-1 inhibition for advanced disease.

Collectively, this experience, while small and uncontrolled, has been encouraging enough to support larger and more robust efforts moving ahead.

\section{DESPITE CONCERNS, SAFETY PROFILE IS GOOD}

Targeting of IL-1 carries several warnings and safety concerns, including risk of serious infection. Overall however, the incidence of serious infection associated with IL-1 inhibitors has been very low, which makes this targeted therapy particularly attractive in the setting of active infection. Isolated cases of atypical infections including fungal and mycobacterial have been reported, however. ${ }^{12}$

Anakinra is used off-label to treat acute gout in the inpatient setting, at a dose of $100 \mathrm{mg}$ subcutaneously daily for 3 to 5 days. The largest observational study of anakinra in this setting found no serious infectious complications in a high-risk cohort of 100 patients that included solid organ transplant recipients and patients with active infection. ${ }^{13}$

Of all the approved IL-1 inhibitors, only canakinumab comes with a recommendation in its package insert to screen for latent tuberculosis before initiating therapy. ${ }^{12}$ Concomitant use of IL-1 inhibitors with TNF inhibitors has been associated with an increased risk for serious infections, so these agents should not be combined. ${ }^{14}$

\section{Laboratory abnormalities}

Anakinra can cause neutropenia, so a neutrophil count is recommended before starting therapy, as is periodic monitoring when using the drug chronically. ${ }^{14}$ Leukopenia, absolute neutropenia, thrombocytopenia, and elevations of hepatic aminotransferases have been reported with use of canakinumab ${ }^{12}$ and thus could be a concern in CRS with advancing cytopenias. Patients treated with rilonacept may experience increases in their mean total cholesterol, high-density lipoprotein, low-density lipoprotein, and triglyceride levels, though this should not be a major concern with short-term use for CRS. ${ }^{15}$

The most common adverse reaction of the drug class is injection site reaction. Safety in pregnancy or breastfeeding has not been established.

\section{OPTIMAL DOSING UNKNOWN}

Despite the lack of evidence of efficacy of targeting IL-1 in COVID-19 from randomized controlled trials, the preliminary reports noted above have been encouraging, and robust trials are underway. Currently registered trials of IL-1-targeting agents are using either anakinra or canakinumab at various doses, as single agents or in combination with other targeted therapies.

Moving ahead, an area of considerable uncertainty is the appropriate dosages and routes of drug administration. This particularly important for anakinra, for which the adequacy of the approved dose of $100 \mathrm{mg}$ by subcutaneous injection once daily for approved indications (Table 1) has come under question for treatment of other cytokine release syndromes such as secondary hemophagocytic lymphohistiocytosis and macrophage activation syndrome. ${ }^{6}$ The largest study of anakinra in COVID-19 concluded that higher doses may be needed, but this conclusion was based on retrospective data. ${ }^{10}$

Currently, most of the registered trials of anakinra for COVID-19 are using higher doses than are generally used for approved indications. Fortunately safety data from large randomized controlled trials of this agent in the setting of sepsis have demonstrated that even very high doses $(3,500 \mathrm{mg}$ daily) can be well tolerated without evidence of infectious complications. ${ }^{16}$ Notably, dosage reduction recommendations for anakinra in the setting of reduced renal function are driven by pharmacokinetic data, not adverse events.

Similarly for canakinumab, the optimal dose for treating cytokine release in COVID-19 is unknown. The approved dosage of $300 \mathrm{mg}$ subcutaneously for periodic fever syndromes and familial Mediterranean fever may not be optimal, and doses up to $600 \mathrm{mg}$ subcutaneously been safely tolerated. ${ }^{17}$ Despite the large experience of targeting IL-1 in other cytokine storm settings, many questions remain unanswered regarding the optimal timing of therapy, in particular regarding how this will be determined, whether on the basis of clinical parameters, biomarkers, or both.

Ideally, treatment and response will be guided by a biomarker, but at present we don't have one. Serum IL-1 levels have been unreliable for monitoring disease activity in hemophagocytic lymphohistiocytosis, and there are as yet no data in COVID-19. A biomarker to predict clinical course is desperately needed. A recently proposed simple algorithm incorporating lactate dehydrogenase, C-reactive protein, and lymphocyte count appears promising but has yet to be applied in prospective trials. ${ }^{18}$

\section{CONCLUSIONS}

Understanding the nature of cytokine release syndrome in COVID-19 is essential if effective therapies are to be developed to lower the mortality rate in 
those with advanced clinical disease. Knowledge of the mere presence of inflammatory biomarkers alone does not provide insight as to what the regulatory defects are that permit this inflammatory state or which mediators may function as drivers or regulators in this complex network. IL-1 is one such mediator, with strong evidence suggesting it may have a central role, but evidence from large, unbiased clinical trials is still awaited. Given the pace of COVID-19 and the global effort to defeat it, such data may be forthcoming soon.

\section{REFERENCES}

1. Calabrese LH. Cytokine storm and the prospects for immunotherapy with COVID-19. Cleve Clin J Med 2020; 87(7):389-393. doi:10.3949/ ccjm.87a.ccc008

2. Henderson LA, Canna SW, Schulert GS, et al. On the alert for cytokine storm: immunopathology in COVID-19. Arthritis Rheumatol (Hoboken, NJ) 2020 Apr 15; 10.1002/art.41285. doi:10.1002/ art.41285

3. Huang C, Wang Y, Li X, et al. Clinical features of patients infected with 2019 novel coronavirus in Wuhan, China. Lancet 2020; 395(10223):497-506. doi:10.1016/S0140-6736(20)30183-5

4. Chen G, Wu D, Guo W, et al. Clinical and immunologic features in severe and moderate forms of coronavirus disease 2019. medRxiv 2020:2020.02.16.20023903. doi:10.1101/2020.02.16.20023903

5. Crayne CB, Albeituni S, Nichols KE, Cron RQ. The immunology of macrophage activation syndrome. Front Immunol 2019; 10:119. doi:10.3389/fimmu.2019.00119

6. Mehta P, Cron RQ, Hartwell J, Manson JJ, Tattersall RS. Silencing the cytokine storm: the use of intravenous anakinra in haemophagocytic lymphohistiocytosis or macrophage activation syndrome. Lancet Rheumatol 2020; 2(6):E358-E367. doi:10.1016/ S2665-9913(20)30096-5

7. Liao M, Liu Y, Yuan J, et al. Single-cell landscape of bronchoalveolar immune cells in patients with COVID-19. Nature Med 2020; 26(6):842-844. doi:10.1038/s41591-020-0901-9

8. Thompson BT, Chambers RC, Liu KD. Acute respiratory distress syndrome. N Engl J Med 2017; 377(19):1904-1905. doi:10.1056/
NEJMc1711824

9. Aouba A, Baldolli A, Geffray L, et al. Targeting the inflammatory cascade with anakinra in moderate to severe COVID-19 pneumonia: case series. Ann Rheum Dis 2020 May 6; annrheumdis-2020-217706. doi:10.1136/annrheumdis-2020-217706

10. Cavalli G, DeLuca GD, Campochiaro C, et al. Interleukin-1 blockade with high-dose anakinra in patients with COVID-19, acute respiratory distress syndrome, and hyperinflammation: a retrospective cohort study. Lancet 2020; 2(6):E325-E331. doi:10.1016/ S2665-9913(20)30127-2

11. Huet $\mathbf{T}$, Beuaussier $\mathbf{H}$, Voisin $\mathbf{O}$, et al. Anakinra for severe forms of COVID-19: a cohort study. Lancet Rheumatol 2020 May 29. doi:10.1016/S2665-9913(20)30164-8

12. Novartis Pharmaceuticals Corporation. Ilaris (canakinumab) package insert, 2016. Accessed June 23, 2020. https://www.accessdata. fda.gov/drugsatfda_docs/label/2016/BLA125319_858687lbl.pdf

13. Liew JW, Gardner GC. Use of anakinra in hospitalized patients with crystal-associated arthritis. J Rheumatol 2019; 46(10):1345-1349. doi:10.3899/jrheum.181018

14. Swedish Orphan Biovitrum AB. Kineret (anakinra) package insert, 2015. Accessed June 23, 2020. https://www.accessdata.fda.gov/ drugsatfda_docs/label/2016/103950s5175lbl.pdf

15. Regeneron Pharmaceuticals. Arcalyst (rilonacept) package insert, 2008. Accessed June 23, 2020. https://www.accessdata.fda.gov/ drugsatfda_docs/label/2008/125249lbl.pdf

16. Shakoory B, Carcillo JA, Chatham WW, et al. Interleukin-1 receptor blockade is associated with reduced mortality in sepsis patients with features of macrophage activation syndrome: reanalysis of a prior phase III trial. Crit Care Med 2016; 44(2):275-281. doi:10.1097/ CCM.0000000000001402

17. Kuemmerle-Deschner JB, Hachulla E, Cartwright R, et al. Twoyear results from an open-label, multicentre, phase III study evaluating the safety and efficacy of canakinumab in patients with cryopyrin-associated periodic syndrome across different severity phenotypes. Ann Rheum Dis 2011; 70(12):2095-2102. doi:10.1136/ ard.2011.152728

18. Yan L, Zhang H, Goncalves J, et al. An interpretable mortality prediction model for COVID-19 patients. Nat Mach Intell 2020; 2:283-288. doi:10.1038/s42256-020-0180-7

Correspondence: Leonard H. Calabrese, DO, Department Rheumatic and Immunologic Diseases, A50, Cleveland Clinic, 9500 Euclid Avenue, Cleveland, $\mathrm{OH}$ 44195; calabrl@ccf.org 